\title{
STUDI KOMPARATIF SENAM KAKI DAN SENAM KEBUGARAN \\ DIABETES TERHADAP KADAR GLUKOSA DARAH SEWAKTU \\ LANSIA DI SLEMAN YOGYAKARTA
}

\author{
Nimsi Melati ${ }^{1}$, Charolina Merlinda $\mathbf{I}^{2}$ \\ ${ }^{(1,2)}$ STIKES Bethesda Yakkum Jl. Johar Nurhadi No. 6 Yogyakarta 524565 \\ Email: nimsi@stikesbethesda.ac.id
}

\begin{abstract}
ABSTRAK
Latar Belakang: Tantangan kesehatan utama saat ini adalah penyakit tidak menular, seperti diabetes mellitus (DM). Tahun 2014 jumlah penderita DM di dunia sebanyak 194 juta jiwa. Penderita yang tidak mampu mengontrol penyakit DM dapat menimbulkan berbagai komplikasi. Pengelolaan dan pencegahan komplikasi DM memerlukan 4 pilar, salah satunya adalah olahraga seperti senam. Tujuan: Untuk mengetahui perbedaan senam kaki dan senam kebugaran diabetes terhadap kadar glukosa darah sewaktu lansia di Sleman Yogyakarta 2017. Metode Penelitian: Penelitian ini menggunakan desain quasi experimental two group pre-post test time series. Teknik sampling menggunakan purposive sampling sebanyak 34 responden, 17 responden senam kaki dan 17 responden senam kebugaran diabetes. Analisis data menggunakan uji General Linier Model Repeated Measures (GLM-RM). Hasil: Hasil uji GLM-RM kelompok senam kaki $p=0,008(p<0,05)$ dan kelompok senam kebugaran diabetes $p=0,003(p<0,05)$, artinya kedua perlakuan berpengaruh terhadap kadar glukosa darah sewaktu lansia. Hasil komparatibilitas GLMRM $p=0,312(p>0,05)$ hal ini menunjukkan bahwa kedua perlakuan tidak memiliki perbedaan terhadap kadar glukosa darah sewaktu. Kesimpulan: Hasil penelitian menunjukan tidak terdapat perbedaan senam kaki dan senam kebugaran diabetes terhadap kadar glukosa darah sewaktu lansia. Saran: Bagi penelitian selanjutnya senam dapat dilakukan dengan frekuensi yang lebih lama untuk mengukur sensitivitas kaki, sensitivitas insulin, dan risiko terjadinya ulkus.
\end{abstract}

Kata kunci : Senam Kaki - Senam Kebugaran Diabetes - Kadar Glukosa Darah Sewaktu.

\section{ABSTRACT}

Background: The current major health challenges are non-communicable diseases such as diabetes mellitus (DM). In 2014 there were 194 million DM patients. Patients who are unable to control the DM can cause various complications. Restraint and prevention of DM complications requires four pillars, one of them is sports like gymnastic. Objective: To know the difference between foot gymnastic and diabetic fitness gymnastic to in time blood glucose level of elderly in Sleman Yogyakarta in 2017. Methode: This was a quasi experimental research with two group pre-post test. There was 34 respondents taken with purposive sampling techique, 17 respondents for foot gymnastic and 17 respondents for diabetic fitness gymnastic. Data analysis used General Linier Model Repeated Measures (GLM-RM). Result: The test result of GLM$R M$ group foot gymnastic $p=0,008(p<0,05)$ and group diabetic fitness gymnastic $p=0,008(p<0,05)$, it means the two treatments have effect to in time blood glucose level of elderly. The results comparatibilitas GLM-RM $p=0,312$ ( $p>0,05)$, it means the two treatment do not have any different effect to in time blood glucose level. Conclusion: The result shows no difference between foot gymnastic and diabetic fitness gymnastic to in time blood glucose level of elderly. Suggestion: For further research the gymnastic can do with a longer frequency to measure foot sensitivity, insulin sensitivity, and risk of ulcers.

Keywords: Foot Gymnastic - Diabetic Fitness Gymnastic - In Time Blood Glucose Level. 


\section{PENDAHULUAN}

Tingkat keberhasilan suatu negara dilihat dari Angka Harapan Hidup (AHH). Peningkatan AHH berdampak pada peningkatan jumlah lanjut usia (lansia). Tantangan kesehatan utama bagi lansia adalah penyakit tidak menular, salah satunya Diabetes mellitus (DM). Data World Health Organization (WHO) tahun 2014 menunjukan bahwa jumlah penderita DM sebanyak 194 juta jiwa (5,1\%) dan jumlah kematian akibat DM sebanyak 3,2 juta jiwa.

Jumlah penderita DM di Indonesia tahun 2013 sebanyak 14 juta jiwa dan hanya 30\% yang berobat secara teratur. Prevalensi penyakit DM di Indonesia berdasarkan usia, yaitu pada usia 45-54 sebesar 9,70\%, usia 55-64 tahun sebesar $11,10 \%$, dan usia 65-74 tahun sebesar 13,20\%. Data Riskesdas tahun 2013, menunjukan bahwa provinsi D.I Yogyakarta menduduki urutan keenam dengan prevalensi 3\%. Data Dinas Kesehatan kabupaten Sleman tahun 2013 Angka kejadian DM pada lansia di Kabupaten Sleman tahun 2012 sejumlah 1.630 kasus.

DM yang tidak terkontrol dengan baik dapat menimbulkan berbagai komplikasi. Pengelolaan dan pencegahan komplikasi DM memerlukan empat pilar utama yang salah satunya yaitu olahraga. Olahraga secara teratur dapat menurunkan kadar glukosa darah. Berbagai olahraga yang dapat dilakukan berdasarkan prinsip Continous, Rhytmical, Interval, Progressive, dan Endurance (CRIPE) yang salah satunya adalah senam. Senam yang dapat dilakukan oleh penderita DM adalah senam kaki dan senam kebugaran diabetes.
Hasil wawancara yang dilaksanakan pada studi awal 14 Oktober 2016, terdapat tujuh penderita umumnya menjawab DM terjadi karena mengkonsumsi makanan dan minuman yang manis serta kurang olahraga atau kurang gerak aktivitas. Tujuh penderita tersebut, empat orang sudah pernah melakukan senam kaki dan dua orang menyatakan tidak melakukan senam kaki, dua orang melakukan senam kebugaran diabetes dan orang mengatakan tidak melakukan senam kebugaran diabetes, sesuai data tersebut, maka peneliti tertarik untuk melakukan penelitian dengan judul "Studi Komparatif Senam Kaki dan Senam Kebugaran Diabetes terhadap Kadar Glukosa Darah Sewaktu Lansia di Sleman Yogyakarta 2017”.

\section{METODE PENELITIAN}

Penelitian ini merupakan penelitian QuasiEksperimen dengan rancangan two group pre-test dan post-test time series design, dilaksanakan di wilayah kerja Puskesmas Ngaglik I Sleman, di balai RT 05/RW 01 kelurahan Minomartani dan balai posyandu Plosokuning dari tanggal 21, 23, dan 25 Mei tahun 2017. Populasi dalam penelitian ini adalah lansia usia 45 - 69 tahun yang menderita DM tipe II di Puskesmas Ngaglik I Sleman dengan jumlah 135 lansia. Teknik pengambilan sampel dengan purposive sampling sebanyak 34 responden. Pembagian sampel menjadi dua kelompok menggunakan teknik random sampling. Alat ukur penelitian standart operasional procedure senam kaki dan senam kebugaran diabetes, serta set glukometer. Analisis data dalam penelitian ini menggunakan General Linier Model Repeated Measures. 


\section{HASIL DAN PEMBAHASAN}

\section{Hasil}

a. Analisis univariat

Tabel 1.

Distribusi Frekuensi Berdasarkan Karakteristik dan Analisa Nilai RataRata Kadar GDS Responden Berdasarkan Usia Lansia di Wilayah Kerja Puskesmas Ngaglik I Sleman 2017

\begin{tabular}{|c|c|c|c|c|}
\hline \multirow[t]{2}{*}{ Variabel } & \multicolumn{2}{|c|}{$\begin{array}{c}\text { Kelompok Senam } \\
\text { Kaki }\end{array}$} & \multicolumn{2}{|c|}{$\begin{array}{c}\text { Kelompok Senam } \\
\text { Kebugaran Diabetes }\end{array}$} \\
\hline & Frekuensi & $\%$ & Frekuensi & $\%$ \\
\hline \multicolumn{5}{|l|}{ Usia } \\
\hline 45-49 tahun & 2 & 11,8 & 2 & 11,8 \\
\hline 50-54 tahun & 2 & 11,8 & 2 & 11,8 \\
\hline 55-59 tahun & 2 & 11,8 & 3 & 17,6 \\
\hline $60-64$ tahun & 6 & 35,3 & 6 & 35,3 \\
\hline $65-69$ tahun & 5 & 29,4 & 4 & 23,5 \\
\hline Total & 17 & 100 & 17 & 100 \\
\hline \multicolumn{5}{|l|}{ Jenis kelamin } \\
\hline Laki-laki & 7 & 41,2 & 7 & 41,2 \\
\hline Perempuan & 10 & 58,8 & 10 & 58,8 \\
\hline Total & 17 & 100 & 17 & 100 \\
\hline \multicolumn{5}{|l|}{ Lama Menderita } \\
\hline $1-5$ tahun & 8 & 47,1 & 7 & 41,2 \\
\hline 6-10 tahun & 6 & 35,3 & 7 & 41,2 \\
\hline $11-15$ tahun & 3 & 17,6 & 3 & 17,6 \\
\hline$>16$ tahun & - & - & - & - \\
\hline Total & 17 & 100 & 17 & 100 \\
\hline \multicolumn{5}{|c|}{ Nilai Rata-Rata Kadar GDS } \\
\hline \multicolumn{5}{|c|}{ Sebelum Senam } \\
\hline$>200 \mathrm{mg} / \mathrm{dl}$ & 5 & 29,4 & 8 & 47,1 \\
\hline $90-199 \mathrm{mg} / \mathrm{dl}$ & 12 & 70,6 & 9 & 52,9 \\
\hline$<90 \mathrm{mg} / \mathrm{dl}$ & - & - & - & - \\
\hline Total & 17 & 100 & 17 & 100 \\
\hline \multicolumn{5}{|c|}{ Nilai Rata-Rata Kadar GDS } \\
\hline \multicolumn{5}{|c|}{ Sesudah Senam } \\
\hline$>200 \mathrm{mg} / \mathrm{dl}$ & 3 & 17,6 & 4 & 23,5 \\
\hline $90-199 \mathrm{mg} / \mathrm{dl}$ & 14 & 82,4 & 13 & 76,5 \\
\hline$<90 \mathrm{mg} / \mathrm{dl}$ & - & - & - & - \\
\hline Total & 17 & 100 & 17 & 100 \\
\hline
\end{tabular}

Sumber: Data primer terolah, 2017.

b. Analisis Bivariat

1) Uji normalitas dalam penelitian ini menggunakan Shapiro Wilk's.

Tabel 2

\begin{tabular}{llccc}
\hline \multicolumn{1}{c}{ Variabel } & \multicolumn{2}{c}{ Nilai $\boldsymbol{p}$} & \\
\cline { 3 - 5 } & & Sebelum & Sesudah & Keterangan \\
\hline $\begin{array}{l}\text { Nilai pengukuran kelompok senam } \\
\text { kaki }\end{array}$ & 0,335 & 0,591 & Normal \\
\hline $\begin{array}{l}\text { Nilai pengukuran senam kelompok } \\
\text { kebugaran diabetes }\end{array}$ & 0,782 & 0,405 & Normal \\
\hline
\end{tabular}

Sumber: Data primer terolah, 2017. 
2) Uji Homogenitas

Uji homogenitas data sebelum dan sesudah perlakuan digunakan Lavene's test.

Tabel 3

\begin{tabular}{lcc}
\hline \multicolumn{1}{c}{ Variabel } & Nilai $\boldsymbol{p}$ & Keterangan \\
\hline $\begin{array}{l}\text { Nilai pengukuran sebelum perlakuan senam kaki dan } \\
\text { senam kebugaran diabetes }\end{array}$ & 0,568 & Homogen \\
\hline $\begin{array}{l}\text { Nilai pengukuran sesudah perlakuan senam kaki dan } \\
\text { senam kebugaran diabetes }\end{array}$ & 0,921 & Homogen \\
\hline $\begin{array}{l}\text { Sumber: Data primer terolah, 2017. } \\
\text { Sumber }\end{array}$ & &
\end{tabular}

3) Uji Hipotesis

Uji hipotesis yang digunakan yaitu uji General Linier Models Repeated Measures.

Tabel 4.

Uji Hipotesis Perbedaan Signifikasi Senam Kaki dan Senam Kebugaran Diabetes terhadap Kadar Glukosa Darah Sewaktu Lansia di Wilayah Kerja Puskesmas Ngaglik I Sleman 2017

\begin{tabular}{lcccc}
\hline Kelompok perlakuan & Mean & $\begin{array}{c}\text { Standart } \\
\text { Deviasi }\end{array}$ & Nama uji & $\begin{array}{c}\text { Signifika } \\
\text { si }(\boldsymbol{p} \text { - } \\
\text { value }\end{array}$ \\
\hline $\begin{array}{l}\text { Kelompok perlakuan } \\
\text { senam kaki }\end{array}$ & 184.05 & 1.779 & $\begin{array}{l}\text { Pillai's Trace } \\
\text { Wilks'Lambda }\end{array}$ & 0,312 \\
& & & Hotelling's Trace & 0,312 \\
\hline $\begin{array}{l}\text { Kelompok perlakuan } \\
\text { senam kebugaran }\end{array}$ & 188.92 & 1.709 & $\begin{array}{c}\text { Roy's Largest } \\
\text { Root }\end{array}$ & 0,312 \\
diabetes & & \multicolumn{3}{c}{}
\end{tabular}

Sumber: Data primer terolah, 2017.

\section{Pembahasan}

Hasil uji GLM-RM diketahui nilai p pada hasil uji analisis adalah 0,312 karena nilai $p$ value $>0,05$ maka dapat disimpulkan tidak terdapat perbedaan pengaruh antara senam kaki dan senam kebugaran diabetes terhadap kadar glukosa darah penderita diabetes mellitus tipe II. Hasil uji GLM-RM dengan Benferroni tidak terdapat perbedaan antara senam kaki dan senam kebugaran diabetes, oleh karena itu asumsi peneliti yang sebelumnya mengatakan senam kebugaran diabetes lebih efektif dibandingkan senam kaki tidak terbukti.
Penurunan kadar glukosa darah sewaktu responden dalam penelitian ini dipengaruhi oleh beberapa faktor antara lain yaitu:

a. Usia

Usia responden dalam penelitian ini yaitu 45-69 tahun dengan prevalensi tertinggi pada rentang usia 60-64 (35,3\%) tahun. Hasil penelitian yang dilakukan oleh Surioka (2012), DM tipe II lebih banyak diderita oleh orang berusia $>50$ tahun daripada orang yang lebih muda, hal ini dikarenakan pada usia $>50$ tahun tejadi penurunan fungsi-fungsi organ tubuh secara keseluruhan. 
b. Jenis Kelamin

Responden kelompok senam kaki dan kelompok senam kebugaran diabetes lebih dari separuh berjenis kelamin perempuan sebanyak 10 responden (58,8\%). Hasil penelitian Santoso dan Nugrahini tahun 2011, proses kehamilan pada perempuan bisa menimbulkan gangguan toleransi glukosa. Hasil penelitian yang dilakukan Saliadeho (2016), mengatakan DM lebih banyak ditemukan pada perempuan karena terjadi penurunan hormon estrogen akibat menopause.

\section{c. Lama Menderita}

Responden dengan prevalensi lama menderita pada kelompok senam kaki sebanyak delapan responden (47,1\%) 1-5 tahun menderita DM tipe II, sedangkan kelompok senam kebugaran diabetes tujuh responden $(41,2 \%)$ 1-5 tahun dan 6-10 tahun menderita DM tipe II. Hasil penelitian oleh Firdaus (2013), ada hubungan antara lama menderita DM dengan terjadinya depresi. Keadaan ini menurunkan kualitas hidup penderita DM tersebut, ini juga disebabkan karena diabetes sering tidak terdeteksi atau mulai terjadinya diabetes adalah tujuh tahun sebelum diagnosis ditegakkan sehingga angka morbiditas dan mortalitas dini terjadi pada kasus yang tidak terdeteksi.

Penderita DM dapat melakukan kedua senam, baik senam kaki maupun senam kebugaran diabetes, karena asumsi penelitian ditolak atau tidak terbukti. Senam kaki maupun senam kebugaran diabetes keduanya efektif untuk menurunkan kadar glukosa darah.

\section{KESIMPULAN}

Berdasarkan hasil penelitian dan uraian pembahasan dapat disimpulkan bahwa:

Tidak terdapat perbedaan secara signifikan pada kelompok perlakuan senam kaki dan senam kebugaran diabetes terhadap penurunan kadar glukosa darah sewaktu lansia dengan p-value 0.312, sehingga asumsi peneliti tidak terpenuhi. Senam kaki dan senam kebugaran diabetes efektif untuk menurunkan kadar glukosa darah sewaktu.

\section{SARAN}

1. Bagi Puskesmas tempat penelitian

Puskesmas dapat mengembangkan dan melaksanakan senam kaki atau senam kebugaran diabetes dalam upaya penanggulangan dan pencegahan terhadap komplikasi DM.

2. Bagi Penelitian selanjutnya Peneliti selanjutnya dapat melakukan kegiatan senam bagi penderita DM dengan frekuensi latihan yang lebih lama untuk melihat perbedaan nilai sensitivitas kaki, Ankle-brachial index (ABI), sensitivitas insulin, dan risiko terjadinya ulkus diabetik.

3. Bagi institusi STIKES Bethesda Yakkum Hasil penelitian dapat menambah referensi bagi mahasiswa keperawatan dalam pemberian pendidikan kesehatan di masyarakat terhadap penatalaksanaan dan pencegahan terhadap penyakit DM dengan menggunakan salah satu pilar DM olahraga atau latihan jasmani.

4. Bagi Masyarakat

Masyarakat terutama penderita DM dapat 
mengaplikasikan senam kaki atau senam kebugaram diabetes secara teratur kadar glukosa darah sewaktu terkontrol, sehingga terjadi perbaikan kondisi kesehatan yang secara langsung dapat meningkatkan kualitas hidup masyarakat.

\section{DAFTAR PUSTAKA}

Arikunto, Suharsimi. (2010). Prosedur Penelitian: Suatu Pendekatan Praktik. Jakarta: Rineka Cipta.

American Diabetes Association. (2013). Position statement: Standards of Medical Care in Diabetes. Diakses pada tanggal 06 Juni 2017 dari http:// care.diabetesjournals.org/content/33/ Supplement_1/S11.full.pdf + htl

Djaja, Sarimawar. (2012). Buletin Penelitian Sistem Kesehatan - Vol. 15 No.4. Jakarta: Kementerian Kesehatan RI. Diakses pada 12 Februari 2017 dari ejournal.litbang.depkes.go.id/indeks. php/hsr/article/view/3030.

Firdaus A. (2013). Hubungan Lamanya Menderita Diabetes Melitus Tipe II Terhadap Tingkat Depresi Pada Pasien Poli Penyakit Dalam RSD Dr. Soebandi Jember. Universitas Jember. Diakses pada tanggal 14 Juni 2017 dari http:// repository. unej. ac.id/ handle/123456789/2342.

Infodatin, Pusat Data \& Informasi Kementerian Kesehatan RI. (2014). Situasi \& Analisis Diabetes. Jakarta Selatan: KEMENKES RI Pusat Data \& Informasi. Diakses pada21 September 2016 dari http://www.d epkes. Go.id/resources/download/ pusdati/infodatin/infodatin-diabetes.pdf
PERKENI (Perkumpulan Endokrinologi Indo-nesia). (2011).Konsensus

Pengelolaan dan Pencegahan Prediabetes. Jakarta: PB Perkeni.

Profil Dinas Kesehatan (DINKES) Kabupaten Sleman. (2013). Diakses pada 08 Maret 2017 dari http:// dinkes.slemankab.go.id/profil-dinaskesehatan-kabupaten-sleman

Rusli, Gusti R. (2015) .Senam Kaki Diabetes Menurunkan Kadar Gula Darah Pasien Diabetes Mellitus Tipe 2. Surabaya: PSIK FIK Universitas Gresik

Saliadeho, A. (2016). Pengaruh Senam Diabetes Terhadap Kadar Gula Darah Penderita Diabetes Tipe 2 Di Sanggar Senam Persadia Kabupaten Gorontalo. Program Studi Ilmu Keperawatan Fakultas Kedokteran UNSRAT. Diakses dari tanggal 07 Juni 2017 dari http:// ejournal.Unsrat.ac.Id/index.php/jkp/ article/ download/11909/11498.

Santoso \& Nugrahini. (2011). Hubungan Aktivitas Fisik Dengan Kadar Gula Darah Pada Pasien Diabetes Mellitus Tipe 2 Di Rumah Sakit Umum Daerah Karanganyar. Universitas Muhammadiyah Surakarta. Diakses pada tanggal 14 Juni 2017 dari http:// eprints.ums.ac.id/29212.

Suiraoka. (2012). Penyakit Degeneratif : mengenal, mencegah dan mengurangi faktor resiko 9 penyakit degeneratif. Yogyakarta : Nusa Medika. 